\section{Desarrollo de fármacos para las enfermedades desatendidas}

Las enfermedades infecciosas tropicales como la malaria, la leishmaniasis, la filariasis linfática, la enfermedad de Chagas o la esquistosomiasis siguen siendo una importante causa de morbilidad y mortalidad, sobre todo en los países en desarrollo, pero la creación de nuevos fármacos para combatir estas enfermedades se encuentra prácticamente detenido. En este artículo los autores analizan las tendencias del desarrollo de nuevos medicamentos a lo largo de los últimos 25 años y las perspectivas existentes para estimular la investigación y desarrollo de nuevos medicamentos contra las enfermedades desatendidas de los países pobres.

Entre 1975 y 1999 se aprobó la comercialización de 1393 nuevas entidades químicas (NEQ), cuya distribución cuantitativa por las diferentes áreas terapéuticas muestra un gran sesgo en favor de los países ricos. En lo que se refiere a las enfermedades infecciosas y parasitarias, que representan un tercio de la carga de morbilidad mundial, pero solo un 5\% de la carga de morbilidad en los países industrializados, el número de NEQ por millón de años de vida ajustados en función de la discapacidad (AVAD) fue de 0,55, mientras que para las principales enfermedades de los países desarrollados fue dos a tres veces mayor: de 1,25 para las enfermedades cardiovasculares a 1,44 para las enfermedades respiratorias no infecciosas. El número de NEQ/millón de AVAD para la totalidad de las enfermedades infecciosas se debió sobre todo a los 20 fármacos antirretrovíricos desarrollados en los últimos 5 a 15 años (0,37 NEQ/millón de AVAD), gracias al serio compromiso político de los países desarrollados y a las grandes inversiones de la industria farmacéutica, estimulada por la gran rentabilidad potencial de estos mercados. En cambio, esta cifra apenas superó $0,1 \mathrm{NEQ} /$ millón de AVAD en el caso de la tuberculosis $(0,11)$, las parasitosis en general $(0,10)$ y la malaria en particular $(0,10)$.

El artículo aporta muchos otros datos igualmente ilustrativos. Por ejemplo:

- Solo 16 de las 1393 NEQ comercializadas entre 1975 y 1999 se destinaron a estas enfermedades: 13 a las enfermedades tropicales y 3 a la tuberculosis.
- En todo el mundo se gastan 307 millones de dólares estadounidenses (\$US) por millón de AVAD en enfermedades respiratorias no infecciosas, frente a $\$ 3$ millones por millón de AVAD en enfermedades tropicales.

- Los medicamentos para las enfermedades cardiovasculares y del sistema nervioso central representan $35 \%$ de las ventas mundiales de medicamentos y $28 \%$ de las 1393 NEQ.

- De los \$35,3 mil millones invertidos por la industria farmacéutica en investigación y desarrollo en 1999, solo 10,1\% se destinó a las enfermedades infecciosas. La inversión total (pública y privada) en investigación y desarrollo de medicamentos para la malaria, la tuberculosis, la leishmaniasis y la tripanosomiasis africana fue inferior a $\$ 70$ millones. Además, el desarrollo de las 16 NEQ mencionadas recibió algún tipo de apoyo del sector público.

- $\mathrm{El}$ 68,7\% de las 1393 NEQ registradas entre 1975 y 1999 presentaron escasas o nulas ventajas terapéuticas con respecto a los fármacos ya existentes, mientras que para las enfermedades desatendidas solo se crearon NEQ innovadoras. Además, las 16 NEQ registradas para tratar las enfermedades desatendidas han sido incluidas en la Lista de Medicamentos Esenciales de la Organización Mundial de la Salud, frente a tan solo $2 \%$ del resto de los medicamentos registrados en el mencionado período.

- El tiempo medio de desarrollo clínico de los medicamentos destinados a combatir las enfermedades desatendidas es mayor que el de los destinados a otras indicaciones.

Pero lo peor es que no hay indicios de que la investigación y desarrollo de medicamentos para las enfermedades desatendidas vaya a mejorar en un futuro cercano. Aunque se han producido importantes adelantos en la comprensión de la fisiopatología y la biología molecular de estas enfermedades, eso no se ha reflejado en la aparición de nuevos productos que cubran las necesidades de los pacientes. Aunque se publica más sobre la biología de las leishmanias y los tripanosomas que sobre cualquier otro parásito, este acervo de conocimientos no ha dado lugar a la aparición de nuevos productos terapéuticos, hecho que se debe sobre todo a inversiones insuficientes en investigación y desarrollo. Por ejemplo, las inversiones 
en la investigación de la malaria (\$42 por caso mortal) son por lo menos 80 veces menores que las inversiones en la investigación del VIH/sida y 20 veces menores que en la investigación del asma. La situación de las demás enfermedades desatendidas es todavía peor que la de la malaria.

Esta situación se explica en gran parte por las leyes del mercado. Así, mientras que los países de la Organización para la Cooperación y el Desarrollo Económico (OCDE) gastan en medicamentos aproximadamente \$239 per cápita al año, la mayoría de los países en desarrollo gastan menos de $\$ 20$ per cápita al año en todos sus programas de salud, incluidos los gastos en medicamentos (en el África subsahariana, la cifra es todavía menor: menos de \$6). Por lo tanto, la industria farmacéutica tiene un gran incentivo para crear fármacos destinados a los países industrializados, pero no a los países en desarrollo. Con el fin de corregir este desequilibrio, se están proponiendo diversas medidas reguladoras del mercado para atraer las inversiones y reinversiones de la industria farmacéutica hacia el campo de las enfermedades desatendidas y se han creado múltiples alianzas entre los sectores público y privado que combinan las capacidades y recursos de uno y otro. No hay duda de que estas medidas son necesarias, pero, según los autores, sus posibles efectos serán probablemente insuficientes para colmar las enormes y crecientes necesidades de salud de las personas pobres de los países en desarrollo.

Por otra parte, los autores opinan que en la actualidad existe un desequilibrio entre los derechos y las obligaciones del sector privado según los acuerdos internacionales en vigor. Por ejemplo, el sector público, que es el principal comprador de medicamentos, le proporciona al sector privado incentivos para la innovación a través de las patentes, pero apenas tiene voz en la elaboración de los programas de investigación de la industria farmacéutica. En este sentido, se podría establecer la obligación de que la industria reinvirtiera un porcentaje de sus beneficios en la investigación y desarrollo de medicamentos para las enfermedades desatendidas.

El Grupo de Trabajo sobre Medicamentos para las Enfermedades Desatendidas (Drugs for $\mathrm{Ne}^{-}$ glected Diseases), del que forman parte los autores de este estudio, está investigando la factibilidad de una iniciativa internacional sin ánimo de lucro que se concentre en los proyectos de desarrollo de medicamentos para las enfermedades más desatendidas y consiga sustraer a la lógica del mercado la investigación y desarrollo de medicamentos que pueden salvar muchas vidas. (Trouiller $\mathrm{P}$, Olliaro $\mathrm{P}$, Torreele E, Orbinski J, Laing R, Ford N. Drug development for neglected diseases: a deficient market and a public-health policy failure. Lancet 2002;359: 2188-2194.)

\section{Primer aislamiento en humanos de un hantavirus, el virus de los Andes, en las Américas}

Los hantavirus son virus de ARN transmitidos por roedores que en el ser humano causan fiebre hemorrágica con síndrome renal o el síndrome pulmonar por hantavirus (SPH). El SPH, causado por los hantavirus del Nuevo Mundo, se caracteriza por presentar cuatro fases: prodrómica febril, cardiopulmonar, diurética y de convalecencia. La fase cardiopulmonar, que suele durar 2 a 10 días, puede ir desde una enfermedad leve hasta una afectación cardiopulmonar grave con insuficiencia respiratoria, acidosis láctica, choque y muerte. En los supervivientes, la diuresis se produce bruscamente y suele asociarse a una rápida mejoría clínica. Las tasas de mortalidad oscilan entre 40 y $50 \%$. El virus de los Andes (ANDV), una especie del género hantavirus de la que es portador Oligoryzomys longicaudatus, es el responsable de la mayoría de los casos de $\mathrm{SPH}$ en Argentina y Chile, mientras que el virus sin nombre (SNV), del que es portador Peromyscus maniculatus, es el principal patógeno en Norteamérica. Aunque no hay pruebas de que el SNV se transmita de persona a persona, sí se ha demostrado este modo de transmisión en el caso del ANDV.

El aislamiento de los hantavirus ha sido difícil tanto en los roedores como, sobre todo, en el ser humano. Con anterioridad, en el ser humano solo se han podido aislar hantavirus de las especies del Viejo Mundo, y nunca en pacientes asintomáticos. En este artículo, los autores describen el primer aislamiento de un hantavirus en el ser humano en el continente americano, y el primer aislamiento de un hantavirus antes del inicio de los síntomas de SPH o de fiebre hemorrágica con síndrome renal.

El caso índice fue una mujer chilena de 54 años que se presentó el 26.08 .99 con cefalea, mialgia y dolor abdominal; 5 días después, el 31.08.99, se le diagnosticó neumonía bilateral con síndrome de dificultad respiratoria del adulto, y falleció al día siguiente. Un hermano de esta paciente también había sufrido enfermedad febril, dolor abdominal agudo, pielonefritis, choque e infiltrados pulmonares bilaterales, falleciendo el 10.08.99. El 13.09.99, el Ministerio de Salud inició un examen rutinario de los contactos familiares y del vecindario, durante el cual se obtuvieron muestras de sangre de 10 personas asintomáticas, entre ellas el nieto de la paciente, de 10 años de edad. El 15.09.99 el niño presentó fiebre y 2 días después la radiografía de tórax mostró intensos infiltrados pulmonares bilaterales; el 18.09.99 fue ingresado con insuficiencia respiratoria y choque, falleciendo pocas horas después, el 19.09.99. 
En este paciente se utilizó la técnica de ELISA con antígenos de la nucleocápside (N) del SNV y del virus de la Laguna Negra (LNV) para detectar la presencia de anticuerpos séricos. El virus se aisló con un método convencional, con tres pases en células Vero E6 monoestratificadas. Las células inoculadas se compararon con células no inoculadas (controles) procesadas en paralelo. Ambos tipos de células fueron examinadas mediante inmunofluorescencia tras la tinción con un anticuerpo policlonal de conejo frente al antígeno $\mathrm{N}$ del ANDV, diluido al 1:1 000. También se utilizó la reacción en cadena de la polimerasa con retrotranscriptasa (RCP-RT) para detectar una porción del gen vírico $\mathrm{N}$ utilizando cebadores genéricos del segmento $\mathrm{S}$. En los estudios filogenéticos, las secuencias de nucleótidos examinadas correspondieron a las posiciones 22 a 359 de la secuencia de sentido antigenómico del gen de la nucleoproteína. Las relaciones genéticas entre este aislado chileno y secuencias homólogas de otros hantavirus caracterizados anteriormente se analizaron con el método de la máxima parsimonia.

La prueba de ELISA no detectó anticuerpos IgG ni IgM. Solo presentaron cuerpos de inclusión inmunofluorescentes las células inoculadas con suero del paciente. Más del $90 \%$ de estas células eran fluorescentes. La especificidad de la reacción se confirmó mediante ELISA y RCP-RT. El producto de la amplificación fue secuenciado y comparado con la secuencia de las cepas prototípicas. El aislado mostró una identidad nucleotídica del $96,2 \%$ con la secuencia prototípica del ANDV, frente a una identidad de tan solo un 81,1 a $82,5 \%$ con el SNV de los Estados Unidos. Por consiguiente, de acuerdo con la secuenciación parcial del segmento S, el aislado es una variante del ANDV.

Este estudio demuestra la presencia de viriones infecciosos de hantavirus en una muestra de suero obtenida 2 días antes del inicio de los síntomas y 6 días antes de la muerte del paciente. Estos resultados indican que la aparición de anticuerpos neutralizantes en las fases iniciales de la enfermedad sintomática podría ser el principal factor responsable de las dificultades para aislar hantavirus en sangre humana una vez que ya se ha iniciado la enfermedad. El hecho de que se pudieran aislar hantavirus 2 días antes del inicio de los síntomas y antes de que se produjeran concentraciones detectables de anticuerpos IgG o IgM indica que puede haber una fase virémica antes de la aparición de los síntomas y que estos podrían deberse más a la respuesta inmunitaria que a la viremia en sí misma. (Galeno H, Mora J, Villagra E, Fernandez J, Hernandez J, Mertz GJ, et al. First human isolate of Hantavirus (Andes virus) in the Americas. Emerg Infect Dis 2002;8:657-661.)

\section{Los anticonceptivos orales y el riesgo de cáncer de mama}

En 1996, un metaanálisis de 54 estudios epidemiológicos sobre el consumo de anticonceptivos orales y el riesgo de cáncer de mama (CM) reveló un ligero aumento del riesgo en las mujeres que estaban tomando anticonceptivos orales (AO), en comparación con las que no los habían tomado: riesgo relativo (RR), 1,24; intervalo de confianza de 95\% (IC95), 1,15 a 1,33. El riesgo también estaba aumentado en las que habían tomado $\mathrm{AO}$ en los últimos 10 años, pero no en las que los habían dejado de tomar hacía más tiempo. Sin embargo, los estudios analizados habían sido publicados a lo largo de un período de 25 años y presentaban importantes diferencias metodológicas, por lo que los autores del presente artículo se propusieron examinar nuevamente este problema.

Para ello realizaron un estudio de casos y controles basado en la población en el que investigaron el papel del consumo de $\mathrm{AO}$ como factor de riesgo de $\mathrm{CM}$ en mujeres de 35 a 64 años y en diferentes subgrupos definidos en función de la edad, la raza, la presencia o ausencia de antecedentes familiares de cáncer de mama y otros factores.

Participaron 4575 mujeres con CM invasor diagnosticado entre 1994 y 1998, y 4682 controles. Las participantes fueron entrevistadas personalmente para obtener información sobre el consumo de $\mathrm{AO}$ y otras hormonas, los antecedentes reproductivos, la salud general y los antecedentes familiares. Los AO se clasificaron como anticonceptivos combinados (estrógenos y progestágenos) o solo progestágenos. Se consideró que contenían altas dosis de estrógenos las formulaciones con dosis de etinilestradiol $\geq 50 \mu \mathrm{g}$ o dosis de mestranol $\geq 75 \mu \mathrm{g}$. Los progestágenos se dividieron en tres grupos: estranos, gonanos y otros. El RR de cáncer de mama se estimó a partir de las razones de probabilidades (odds ratios), calculadas mediante regresión logística condicional. No obstante, para facilitar su presentación, los autores comentan los datos como RR, y no como razones de probabilidades. Se consideraron estadísticamente significativos los valores de $P \geq 0,05$.

Además del lugar de estudio, la raza y la edad, se analizaron ocho posibles factores de confusión: nivel educacional, ingresos, ejercicio físico semanal, número de biopsias mamarias, duración de la lactancia materna, tabaquismo, cantidad de alcohol consumida y presencia o ausencia de antecedentes de esterilización tubárica, mamografía, enfermedades médicas importantes e inyecciones o implantes de anticonceptivos. Como ninguno de estos factores adicionales alteró las estimaciones, se excluyeron de los modelos. 
El 65\% de las mujeres eran blancas y el 35\%, negras. Los casos y los controles presentaron diferencias significativas con respecto a la distribución de múltiples características, como el número de embarazos a término y la presencia o ausencia de antecedentes familiares de CM. El 77\% de los casos y el 79\% de los controles habían tomado algún tipo de AO.

El RR fue de 1,0 (IC95: 0,8 a 1,3) para las mujeres que estaban consumiendo $\mathrm{AO}$ en la actualidad, $\mathrm{y}$ de 0,9 (IC95: 0,8 a 1,0) para las que los habían consumido con anterioridad. El RR no aumentó de forma homogénea con la duración del consumo ni con las dosis de estrógenos. Tampoco hubo diferencias en función del tipo de progestágeno. Los resultados fueron similares en las mujeres de raza negra y blanca. El consumo de $\mathrm{AO}$ por las mujeres con antecedentes familiares de $\mathrm{CM}$ no se asoció a un aumento del riesgo de CM. Al examinar varios aspectos del consumo (actual, pasado o en cualquier momento; duración; edad de inicio; tiempo transcurrido desde que se dejaron de tomar, y dosis de estrógenos), tampoco se obtuvieron pruebas de que los $\mathrm{AO}$ aumenten el riesgo. Los resultados fueron muy similares en las mujeres de 35 a 44 años y en las de 45 a 64 años. El RR tuvo tendencia a ser mayor en las mujeres que seguían tomando AO en la actualidad que en las que ya habían dejado de tomarlos, pero fue similar en estas y en las que nunca los habían tomado. También se realizó un análisis para determinar si el riesgo de $\mathrm{CM}$ asociado al consumo de $\mathrm{AO}$ variaba en función de la presencia $o$ ausencia de antecedentes familiares de CM, del índice de masa corporal o del estado menopáusico. Los resultados obtenidos en estos subgrupos fueron similares a los del análisis global.

Los autores concluyen que el consumo actual o pasado de AO no incrementa de forma significativa el riesgo de $\mathrm{CM}$ en mujeres de 35 a 64 años. Este resultado es de enorme importancia para la salud pública, dado que más de $75 \%$ de las cerca de 10000 participantes en este estudio habían consumido AO. Con una exposición tan alta, incluso un pequeño aumento del riesgo podría suponer un número considerable del número de nuevos casos de $\mathrm{CM}$. El hecho de que el estudio haya estado basado en la población reduce el riesgo de introducir sesgos en la selección de los casos y los controles. (Marchbanks PA, McDonald JA, Wilson HG, Folger SG, Mandel MG, Daling JR, et al. Oral contraceptives and the risk of breast cancer. N Engl J Med 2002;346:2025-2032.)

\section{Un nuevo método, más sensible, para detectar huevos de helmintos en heces}

El análisis de las heces para detectar la presencia de huevos de parásitos es un procedimiento fundamental del examen clínico básico y un componente clave de los estudios epidemiológicos sobre los helmintos intestinales. La técnica de KatoKatz es la utilizada habitualmente para diagnosticar la infestación por Schistosoma mansoni. Sin embargo, su sensibilidad depende de la consistencia de las heces, lo cual limita su valor y puede comprometer su uso en los ensayos clínicos sobre las vacunas frente a $S$. mansoni, sobre todo cuando la vacunación está destinada a reducir parcialmente la producción de huevos por los parásitos adultos, más que a anularla completamente.

Para superar estas limitaciones, los autores de este estudio idearon y validaron una nueva técnica de separación de los huevos de helmintos, basada en la mayor densidad de los huevos viables en comparación con las heces. Después de centrifugar la muestra de heces durante $15 \mathrm{~min}$ en una solución de $\mathrm{NaCl}$ al $0,9 \% /$ Percoll $^{\circledR}$, se eliminan las partículas mayores por filtración y se transfieren los huevos a un portaobjetos y se cuentan con un microscopio de 40 aumentos en presencia de verde de malaquita al $1 / 10$. Los resultados obtenidos con esta técnica se compararon con los proporcionados por los frotis de Kato-Katz.

Primero se analizaron muestras triplicadas de heces de 12 primates infectados experimentalmente con S. mansoni. La técnica de centrifugación en Per$\mathrm{coll}^{\circledR}$ detectó la presencia de huevos en las heces de 11 de los 12 animales y los recuentos presentaron una alta repetibilidad. Los restos fecales presentes, que fueron sobre todo fibras vegetales, no interfirieron con el recuento. En cambio, los frotis de Kato-Katz preparados con las mismas muestras de heces solo identificaron la presencia de huevos en 3 de $\operatorname{los} 12$ animales, y los recuentos fueron unas 20 a 40 veces menores que con la técnica de centrifugación en Percoll ${ }^{\circledR}$, hecho que se puede explicar, al menos en parte, por el mal rendimiento de estos frotis en heces con muchos restos de fibra.

A continuación se realizó en 27 pacientes con esquistosomiasis un análisis comparativo similar que demostró que la infestación de baja intensidad ( $<100$ huevos/g) solo era detectada de forma eficiente por la técnica de centrifugación en Percoll ${ }^{\circledR}$, que proporcionó siempre recuentos de huevos superiores a los registrados con la técnica convencional de Kato-Katz y mostró menos variabilidad.

Los resultados obtenidos indican que la técnica de Kato-Katz tiene un límite de aproximadamente 100 huevos/g, por debajo del cual las infecciones no se pueden detectar de forma fiable. Por consiguiente, la prevalencia y la intensidad de la infestación por S. mansoni en las áreas endémicas se podrían estar subestimando sistemáticamente en el diagnóstico rutinario, debido al mal rendimiento de la técnica de Kato-Katz. La nueva técnica de centri- 
fugación en Percoll ${ }^{\circledR}$ descrita en este artículo constituye una buena alternativa para el diagnóstico de la esquistosomiasis. Aunque puede no ser adecuada para los estudios de campo a gran escala debido a la necesidad de disponer de una balanza de precisión y de una centrifugadora de laboratorio, es una técnica simple, sensible y exacta que podría ser adoptada por los servicios diagnósticos centrales. Además, podría ser muy útil en los ensayos clínicos sobre las vacunas contra $S$. mansoni, en los que es imprescindible realizar estimaciones fiables de los recuentos de huevos en heces. Por último, la técnica descrita permite detectar la presencia de huevos no solo de S. mansoni, sino también de muchos otros helmintos patógenos, como Ascaris lumbricoides, Trichuris trichiura, Enterobius vermicularis, Hymenolepis nana y Fasciola hepatica. (Eberl M, al-Sherbiny M, Hagan P, Ljubojevic S, Thomas AW, Wilson RA. A novel and sensitive method to monitor helminth infections by faecal sampling. Acta Tropica 2002; 83:183-187.)

\section{Suplementos de vitamina $\mathrm{E}$ y degeneración macular}

La degeneración macular relacionada con la edad (DME) es actualmente la principal causa de pérdida de visión y ceguera en los países desarrollados. Esto se debe tanto al envejecimiento de la población como al éxito del tratamiento de otras causas de ceguera, tales como la oftalmia neonatal, la catarata y la retinopatía diabética. La prevalencia aumenta rápidamente en los mayores de 60 años, de tal modo que dos tercios de los mayores de 90 años tienen DME y $25 \%$ de estos se quedan ciegos. Su causa sigue siendo desconocida, aunque se sabe que un tercio de los casos se asocian al tabaquismo, y el tratamiento solo es parcialmente eficaz, y no en todos los casos. Además, tampoco hay un método profiláctico eficaz. El objetivo de este estudio aleatorizado, controlado y doblemente enmascarado consistió en determinar si los suplementos de altas dosis de vitamina E influyen en la aparición y progresión de la DME.

Los participantes fueron voluntarios sanos de 55 a 80 años reclutados entre enero de 1995 y abril de 1996. De las 1906 personas entrevistadas telefónicamente, 1289 (69\%) fueron examinadas, y 1204 de estas (93\%) fueron asignadas aleatoriamente al tratamiento diario durante 4 años con una suspensión de 500 UI de vitamina E natural $(335 \mathrm{mg}$ de D-tocoferol) en aceite de soja, en cápsulas, o solo con aceite de soja (placebo), en cápsulas idénticas. Se planearon exámenes anuales y el seguimiento fi- nalizó en enero de 2000. La principal medida de eficacia fue la aparición de DME precoz (DME 3) en las retinografías. Otras medidas de eficacia consistieron en definiciones alternativas de la DME, su progresión, los cambios de sus componentes, la agudeza visual y la función visual.

En el análisis se incluyeron 1193 participantes. Los dos grupos eran muy similares y no presentaban diferencias en sus características basales. Se obtuvo una alta tasa (73\%) de cumplimiento del tratamiento y de las consultas previstas, similar en ambos grupos. No se registraron acontecimientos adversos graves y no hubo diferencias entre los grupos con respecto al número total ni al tipo de acontecimientos adversos.

La incidencia de DME precoz fue de $8,6 \%$ en las personas tratadas con vitamina $\mathrm{E}$, frente a $8,1 \%$ en los que recibieron placebo [riesgo relativo (RR): 1,05; intervalo de confianza de 95\% (IC95): 0,69 a $1,61]$, y la de DME tardía, de $0,8 \%$ frente a $0,6 \%$, respectivamente (RR: 1,36; IC95: 0,67 a 2,77). El análisis de las medidas de eficacia secundarias tampoco mostró diferencias entre los grupos. De acuerdo con la clasificación de las retinografías, se observó progresión en 95 de los 491 (19\%) casos tratados con vitamina $\mathrm{E}$ y en 90 de los $506(18 \%)$ que recibieron placebo (RR: 1,09; IC95: 0,84 a 1,42). Con la clasificación clínica de la progresión tampoco se observaron diferencias entre los grupos: $7,9 \%$ en el tratado con vitamina $\mathrm{E}$ y $6,0 \%$ en el tratado con placebo (RR: 1,31; IC95: 0,83 a 2,07).

Este es, según los autores, el primer estudio aleatorizado controlado sobre los suplementos de vitamina $E$ en la DME. Sus puntos fuertes son el tamaño de la muestra, la alta tasa de cumplimiento del tratamiento y del seguimiento, su carácter aleatorizado y la documentación fotográfica de los cambios, y sus debilidades, la duración relativamente corta del seguimiento (4 años) y la proporción relativamente baja de fumadores. La ausencia de efectos protectores de la vitamina $\mathrm{E}$ en este estudio puede deberse precisamente a la brevedad del período del seguimiento. También es posible que los antioxidantes solo sean eficaces en algunos subgrupos de personas con un riesgo especial o con una gran exposición a la oxidación y a las lesiones retinianas, como aquellos con predisposición genética, los fumadores o aquellos con gran exposición ocular a la luz. Por último, no se puede descartar la posibilidad de que la vitamina E no desempeñe un papel importante en la protección frente a la degeneración macular. (Taylor HR, Tikellis G, Robman LD, McCarty CA, McNeil JJ. Vitamin E supplementation and macular degeneration: randomised controlled trial. BMJ 2002;325:11-14.) 